\title{
Combining local knowledge and occupancy analysis for a rapid assessment of the forest elephant Loxodonta cyclotis in Cameroon's timber production forests
}

\author{
Stephanie Brittain, Madeleine Ngo Bata, Paul De Ornellas, \\ E. J. Milner-Gulland and Marcus RowChiffe
}

\begin{abstract}
Information on the distribution and abundance of the forest elephant Loxodonta cyclotis is needed to allocate limited resources appropriately and set conservation goals for the species. However, monitoring at large scales in forest habitats is complicated, expensive and time consuming. We investigated the potential of applying interview-based occupancy analysis as a tool for the rapid assessment of the distribution and relative abundance of forest elephants in eastern Cameroon. Using single-season occupancy models, we explored the covariates that affect forest elephant occupancy and detectability, and identified spatial and temporal patterns in population change and occupancy. Quantitative and qualitative socio-demographic data offer additional depth and understanding, placing the occupancy analysis in context and providing valuable information to guide conservation action. Detectability of forest elephants has decreased since 2008, which is consistent with the decline in perceived abundance in occupied sites. Forest elephants occupy areas outside protected areas and outside the known elephant range defined by IUCN. Critical conservation attention is required to assess forest elephant populations and the threats they face in these poorly understood areas. Interview-based occupancy analysis is a reliable and suitable method for a rapid assessment of forest elephant occupancy on a large scale, as a complement to, or the first stage in, a monitoring process.
\end{abstract}

Keywords Cameroon, Central Africa, forest elephant, illegal killing, interviews, ivory, logging, population monitoring

Supplementary material for this article is available at https://doi.org/10.1017/So030605317001569

Stephanie BritTAin ${ }^{*}$ (Corresponding author) Imperial College London, Silwood Park Campus, Sunningdale, UK. E-mail Stephanie.brittain@zoo.ox.ac.uk

Madeleine Ngo Bata Zoological Society of London, Bastos, Yaoundé, Cameroon Paul De Ornellas Africa Conservation Programmes, ZSL London Zoo, Regent's Park, London, UK

E. J. MilneR-Gulland Department of Zoology, University of Oxford, UK

Marcus Rowcliffe Institute of Zoology, Zoological Society of London, Regent's Park, London, UK

${ }^{*}$ Current address: Department of Zoology, University of Oxford, New Radcliffe House, Walton Street, Oxford, OX2 6AE, UK

Received 16 May 2017. Revision requested 27 June 2017.

Accepted 4 October 2017. First published online 19 March 2018.

\section{Introduction}

Arican forest elephants Loxodonta cyclotis are under A threat. According to data analysed by the CITES Elephant Trade Information System and Monitoring the Illegal Killing of Elephants programmes, the illegal trade in ivory is escalating (Milliken et al., 2009) and offtake exceeds calculated sustainable levels (CITES, 2015). 2013 was the worst year on record for ivory seizures, with almost 50 tons seized (Vira et al., 2014). Central Africa remains the sub-region with the highest poaching pressure on the continent (CITES, 2015). Although forest elephants are taxonomically and functionally unique, IUCN recognizes only one species of African elephant Loxodonta africana, which is categorized as Vulnerable on the IUCN Red List (Blanc, 2008). However, there is significant geographical variation in the level of threat, and based on a regional assessment the Central African forest elephant is Endangered (Blanc et al., 2007).

Population status and distribution assessments are required to set goals and measure the effectiveness of management actions (Blanc et al., 2007). Several such assessments of forest elephants have been carried out (Schuttler et al., 2012; de Boer et al., 2013; Maisels et al., 2013); however, given their cryptic nature, large range within dense forest habitat, and low encounter rates, monitoring the distribution and trends of forest elephants remains a challenge (Hedges, 2012). Transect surveys of dung density are the most widely used method (Barnes, 2001; Blake et al., 2007) but this is arduous and has been applied to only a relatively small part of the species' range (Boafo et al., 2009).

Given these constraints, the scale of decline of forest elephants in Central Africa has been difficult to quantify, and this lack of information is a key concern for their conservation (Karanth et al., 2003; Blake \& Hedges, 2004; Sutherland et al., 2004; Blake, 2005; Blanc et al., 2007). With 51\% of Cameroon's potential elephant range unmonitored, it is vital that the country's forests are surveyed to address this knowledge gap, resolve uncertainty and guide conservation action.

There is potential for using local ecological knowledge to assess the status and distribution of forest elephants by gathering data rapidly over areas and timescales, which would not be feasible using conventional surveys (Danielsen et al., 2005; Jones et al., 2008; Mohd-Azlan 
et al., 2013; Turvey et al., 2013, 2015; Service et al., 2014). As local people often frequent areas that are relatively inaccessible (Service et al., 2014), the likelihood of obtaining species encounter records can be increased substantially by questioning local people, and this is especially useful for wideranging and elusive species (Turvey et al., 2013, 2015; Service et al., 2014). Local ecological knowledge can also facilitate a better understanding of threats to species (Abram et al., 2015), resulting in faster decision-making (Danielsen et al., 2010) through increased dialogue (Belant et al., 2013; Mohd-Azlan, 2013).

Data collected from local knowledge are comparable with those collected using conventional methods (Danielsen et al., 2005; Jones et al., 2008; Meijaard et al., 2011; Turvey et al., 2013; Pan et al., 2015; Parry \& Peres, 2015). All methods are susceptible to biases and uncertainties, and it is important to understand these biases to control for them (Danielsen et al., 2000; Jones et al., 2008). Observer and biophysical variables are a concern for most conventional population monitoring methods (Buckland et al., 2001; Sethi et al., 2005; Nuno et al., 2013). Characteristics of observers, such as age (Turvey et al., 2010) and experience (Cerqueira et al., 2013), can influence ability to detect a species accurately. Furthermore, respondent biases, for example driven by social norms, can cause deception or unconscious distortion of responses (Moller et al., 2004). Fishers may deliberately overestimate their catch (Lunn \& Dearden, 2006), and local people who are adept at finding a species may overestimate its population size if it is considered to be common (Moller et al., 2004).

Heterogeneous habitat type (Tracey et al., 2005), survey time (Cerqueira et al., 2013), seasonality (Blanc et al., 2007), or variations in animal abundance (Royle \& Nichols, 2003) can influence the effectiveness of population survey methods by affecting species detectability along gradients that may also influence abundance (Sutherland, 2006). Observer and biophysical variables must therefore be controlled to reach an unbiased estimate of species distribution and relative abundance.

Occupancy indices are widely used for large-scale monitoring programmes because they are relatively inexpensive and easy to implement compared to estimates of absolute abundance (Royle \& Nichols, 2003; Joseph et al., 2006). Occupancy indices also benefit from being able to control for uncertainties associated with detectability, providing unbiased estimates of the likelihood of species presence in time and space (MacKenzie et al., 2006). Occupancy is an estimate of the probability that a species occupies, or uses, a particular sample unit during a specified period of time during which the occupancy state is assumed to be static (Bailey et al., 2004). Using the maximum likelihood occupancy model both detectability and occupancy can be estimated in a single-model framework by building a detection history (MacKenzie et al., 2002), which potentially includes covariates of occupancy and detectability within the framework (Wintle et al., 2012).

Surveys of local people have been combined with occupancy analysis to rapidly assess the status of multiple species over time (Pillay et al., 2011; D’Souza et al., 2013) and at large spatial scales (Martinez Marti, 2011; Puri et al., 2015). Here we combine semi-structured interviews of timber industry employees across eastern Cameroon (Fig. 1) with occupancy analysis to assess large-scale distribution and trends in forest elephant populations over time. We focused on areas categorized as unknown by the IUCN African Elephant Database (IUCN/SSC, 2013), to obtain new information about the range of elephants in these areas (Fig. 1). Timber concessions are an important but under-researched habitat for elephants, comprising $60-80 \%$ of the eastern region (Bikié et al., 200o). We aimed to (1) assess the distribution and trends in forest elephant populations over 6 years across $30,000 \mathrm{~km}^{2}$ of eastern Cameroon using interviewbased occupancy analysis, (2) assess the reliability and suitability of this method of rapid assessment in the context of forest elephants in Africa, and (3) make recommendations for conservation action in the study area.

\section{Methods}

Timber concessions are divided into well-defined and demarcated forest management units (Cerutti et al., 2016). Each forest management unit is divided into 30 annual allowable cuts, of which one can be exploited each year over 30 years. Sites were defined as annual allowable cuts, as these are familiar to respondents and are approximately equal in size $\left(\right.$ c. $\left.5 \mathrm{~km}^{2}\right)$. Maps of the forest management units were obtained from each concession manager prior to conducting interviews and each site's year of exploitation was clearly marked. Respondents stated in which site they had worked, in which year, and whether or not they had seen signs of elephants, and the maps helped them to recall fine-scale temporal and spatial data relevant to a particular site.

We conducted interviews with timber concession workers, local people and administrative authorities, using a targeted, opportunistic sampling strategy to select respondents. Although the external validity of data obtained through this strategy is low (Sapsford \& Jupp, 1996), timber concession workers are a valuable source of knowledge, given the extent of concessions and their potential value as conservation land (Lamb et al., 2005).

Interviews with administrative authorities were conducted to triangulate the data collected from timber concession workers and to obtain data on incidents of poaching. Chefs de poste of the Ministry of Forests and Wildlife, the governmental department responsible for the protection of forested areas and its biodiversity in Cameroon, should be aware of any reported poaching and can therefore give 

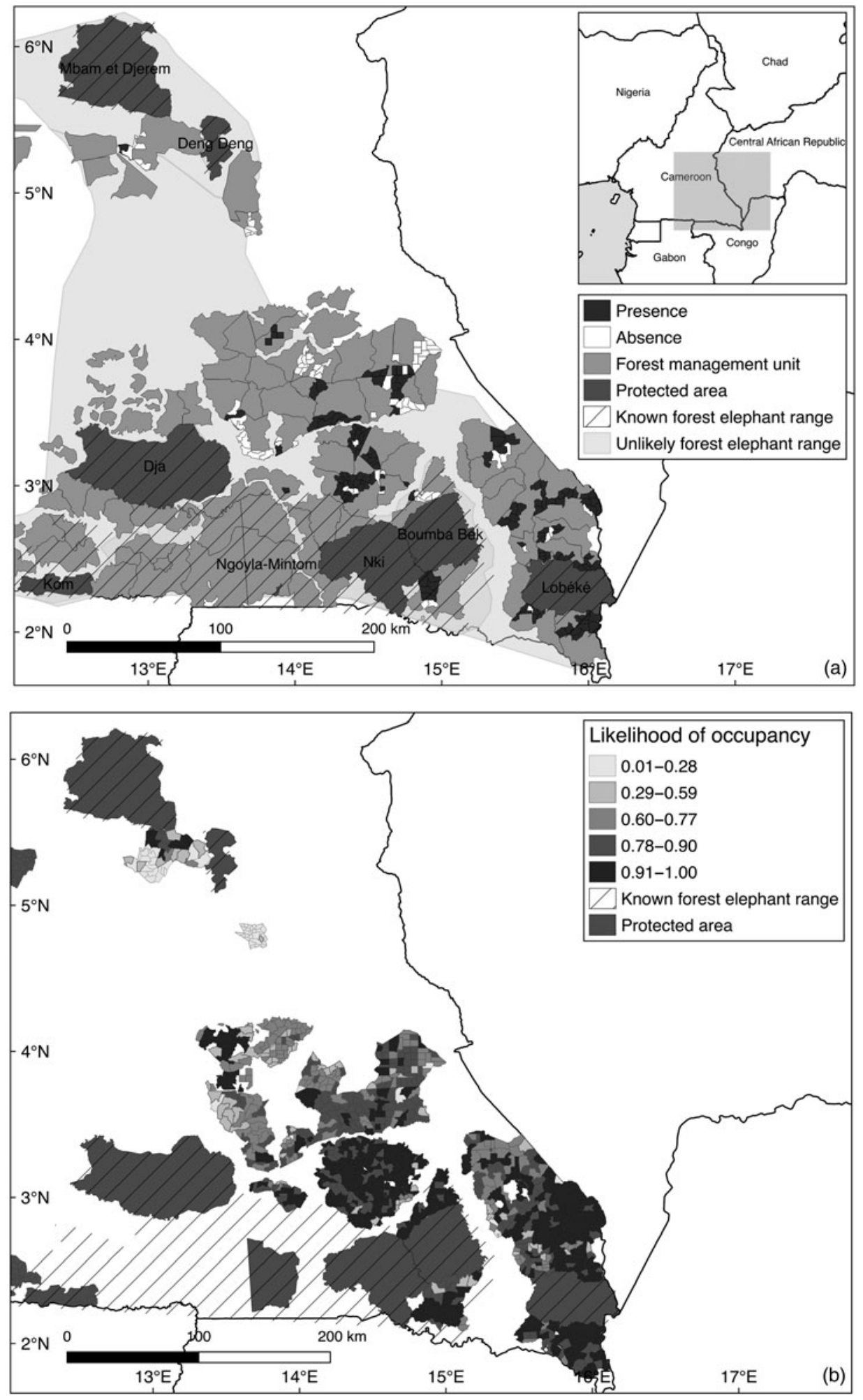

FIG. 1 (a) The study area in eastern Cameroon, including the known forest elephant range and areas deemed unlikely to be forest elephant range by IUCN/SSC (2013), and (b) likelihood of occupancy.

an alternative perspective on the research questions. Managers of the Department of Fauna, the managers of the eastern region departments and the chefs de poste from the Ministry of Forests and Wildlife were interviewed.

A simple questionnaire was administered to timber concession workers and authorities during 12 May-30
June 2013, to elicit their observations of elephants during 2008-2013 (Supplementary Material 1). The interviews were designed to be easily replicated and administered, whilst retaining standardization. A combination of closed and open-ended questions facilitated quantitative and qualitative analysis. 
A shortened version of the semi-structured questionnaire used for timber concession workers was used to guide interviews with administrative authorities, retaining the sections on estimated abundance, distribution and threats, to collect qualitative data. Informal interviews (Newing et al., 2011), using open-ended questions, were conducted on several occasions to gather qualitative information on changes in the forest elephant population, and threats and attitudes towards elephants. The direction of the conversation was led by the interviewee, with the interviewer asking some questions to guide the conversation or probe an interesting point. Key details were recorded immediately after the conversation.

Efforts were made both in the design of the survey and the interview process to minimize or control for respondent bias. For each participating timber concession an initial meeting was held with the site manager, who helped us to identify which teams entered the forest on foot and did not operate machinery, and therefore had the best chance of spotting and correctly identifying signs of elephant presence. To select a subset of the most reliable workers from within the identified teams, a series of short questions were administered to focus groups to eliminate unsuitable respondents (Supplementary Fig. 2).

Selected respondents were interviewed individually to prevent audience effect bias. Questions were phrased neutrally to reduce deference effect bias (Newing et al., 2011) and respondents were asked to report on their own experience only. No specific reference to elephants was made at the start of the interview, to reduce order effect bias, and care was taken to use the interview funnel approach (Newing et al., 2011). The reliability of reported detections was validated by asking respondents to repeat both their detection and non-detection responses at the end of the interview and to describe the reported signs to ensure that the species had been identified correctly. If the respondent appeared to be unsure or gave different responses, the response was excluded from analysis.

Occupancy models were constructed, in which the response variable was whether the interviewee had observed elephants or their sign in a given annual allowable cut at any time during the study period. Given the rotational nature of exploitation within forest management units, repeat data from the same site over different years were not collected frequently enough to conduct multi-season occupancy analysis (MacKenzie et al., 2003). Therefore, singleseason occupancy analysis was carried out, by treating each site-year combination as a site in the detection matrix. Year could then be included as a covariate in the occupancy analysis to identify trends in detectability and occupancy over time, with a year considered to be the closure period, over which occupancy was assumed to be constant. The period 2008-2013 was chosen because the volume of reliable data was considerably less prior to 2008 (respondents were unsure when asked to repeat their responses at the end of the interview), and the number of respondents who had been employed prior to 2008 decreased. Following Martinez Marti (2011), individual interviewees were treated as effective repeat surveys for occupancy analysis. The number of respondents varied considerably between concessions. Although occupancy analysis accounts for missing data, sites with only one respondent were excluded from analysis and sites that did not meet the minimum of four replicates were treated with caution during analysis and discussion (MacKenzie et al., 2002).

Forest management unit group (central, south-eastern, south-western, northern; Supplementary Fig. 1) was included as a factor in analysis, facilitating comparisons of occupancy and detectability between groups. The groups are spatially distinct, separated by well-used roads and villages. Data on reported elephant tracks, broken branches, dung, carcasses and direct sightings were included in analysis to build a detection history for each site. Respondents who reported having seen a sign were asked to describe what they saw, as a means of verification. Only signs or direct sightings seen by the interviewee were included, as sightings related by others were considered to be hearsay and unreliable.

Given the easily identifiable signs of forest elephants and the controls put in place to ensure the reliability of the respondents selected, we felt false positives were unlikely, and therefore occupancy models that account for false positive detections were not deemed necessary for this study. Given the sample unit size relative to elephant home range, occupancy estimates cannot be considered to reflect the probability of long-term residence. Rather, we interpret occupancy as the proportion of area used (MacKenzie \& Royle, 2005; Martinez Marti, 2011).

Maps of site-level occupancy covariates were prepared using ArcGIS 10.o (ESRI, Redlands, USA), and the respondent detectability covariates were obtained from each interview. Pairwise correlations were conducted to examine the independence of variables and eliminate any covariates that were too closely associated to be modelled together. Spearman's rank and Shapiro-Wilk tests were used to check for normal distribution of the continuous geographical variables. Spearman's correlation coefficient was used to test the relationship between the non-normally distributed variables. Pearson's correlation coefficient for parametric data was used for the remaining normally distributed variables. There was a strong positive correlation between age of respondent and number of trips made to the forest $(\rho=0.98)$ and between the number of years the respondent had worked in the concession and number of trips made to the forest $(\rho=0.91$; Supplementary Table 1$)$. The variable 'number of trips' was therefore not included in the models. There were no significant correlations between the covariates for the occupancy part of the model (Supplementary Table 2). Year of observation and forest management unit 
group were included as covariates for both occupancy and detectability to control for forest management unit-level variation in detectability (MacKenzie, 2006). Other covariates were included based on their hypothesized relationship with occupancy or detectability (Supplementary Table 3).

The Akaike Information Criterion (Burnham \& Anderson, 2002) was used to identify the best-fit models that account for detectability $(\rho)$, keeping the global model for occupancy ( $\psi$ ) (Supplementary Table 4 ). Using the best-fit model for $\rho$, occupancy was modelled to find the best-fit model for both $\rho$ and $\psi$. The MacKenzie \& Bailey (2004) goodness-of-fit bootstrap test was run to evaluate the best-fit model and to draw inferences to explain the effect of the covariates on $\rho$ and $\psi$. All occupancy analysis was conducted in $R$ v. 2.15.3 (R Development Core Team, 2017), using the package unmarked (Fiske \& Chandler, 2011).

Change in relative abundance over time was calculated based on the relationship between detection probability of individual elephants $(r)$, site population size $(N)$ and pervisit detection probability $(\mathrm{P})$, proposed by Royle \& Nichols (2003):

$$
\mathrm{P}=1(1-r)^{N} .
$$

Given detection probabilities estimated in years $i=1$, $2, \ldots 6$, year-specific populations are given by:

$$
N_{i}=\log \left(1-p_{i}\right) / \log (1-r) .
$$

Assuming constant $r$, population size in year $i$ relative to year 1 is therefore given by:

$$
N_{i} / N_{1}=\log \left(1-p_{i}\right) / \log \left(1-p_{1}\right) .
$$

For interviews we followed the ethical guidelines of the Social Research Association (2003). The interview team (SB and MNB) spoke French to ensure accurate communication. All respondents were guaranteed confidentiality and anonymity, and free, prior, informed consent was obtained. Interviews were recorded if permission was given $(>95 \%$ of respondents agreed). Otherwise, notes were taken and transcribed immediately post interview. Given the sensitive nature of the topic, no participants were asked if they had taken part in any illegal activities. We conducted a pilot study during 4-11 May 2013 to test the methodologies and sampling strategy, aiming to make any necessary adjustments to the approach and assess the reliability of the responses. The pilot study was conducted in a timber concession for which robust data on elephant presence were available.

\section{Results}

Of the 182 respondents interviewed, 161 were timber concession workers and 16 were administrative authorities; five informal interviews were conducted with researchers, poachers and hunting zone owners. Prior to analysis seven timber concession workers ( $4 \%)$ were deemed unreliable and their data were removed, leaving a total of 175 responses.

Survey responses suggested that interviewees were likely to be able to distinguish elephant signs in the field; $96 \%$ of respondents were raised in rural villages and $76 \%$ attributed their knowledge of animal signs to their fathers or upbringing. Respondents gave information about elephant observations at 342 sites within 34 forest management units. We interviewed $1-25$ respondents per site $($ mean $=4.82)$. Fig. 1 shows the distribution of reported detections and nondetections, suggesting the forest elephant's range extends further north and east of the current known elephant range (IUCN/SSC, 2013). There is a higher proportion of sites with reported detections in the south-western and south-eastern forest management unit groups than in the central and northern groups.

The null model, assuming constant occupancy and detectability, estimated occupancy $(\Psi$, probability that a given site was used by elephants) to be 0.76 , and detectability $(\mathrm{P}$, probability that use of a forest management unit by elephants would be detected by a respondent) 0.58 (Supplementary Table 6).

The most parsimonious model with covariates that best described occupancy and detectability included, for detectability, the number of nights that the respondent camped in the forest when working, the number of years they had worked in the concession, the forest management unit group and year (Table 1). The occupancy variables included were the distance of the village from the centre of each annual allowable cut, the distance of the annual allowable cut from the nearest river and road, the elevation of the annual allowable cut, and the forest management unit group. A goodness-of-fit test found no significant lack of fit $(\mathrm{P}=0.8)$.

Occupancy was not strongly affected by any of the explanatory variables but, as expected (Supplementary Table 4), it was higher in areas further from villages and roads and closer to rivers. It did not vary significantly between forest management unit groups. Detectability, however, had a number of strong associations, including that those who camped for up to a week at a time in the forest were more likely to detect elephants than those who did not camp or who camped for longer, that detectability was much higher in the south-western and south-eastern forest management groups, and that there was a strong and consistent decline in detectability over time (Table 2). All sites had a similar forest environment; therefore, any spatial variation in the ability to detect the species cannot be explained by changes in habitat type or visibility. The same measures were put in place in each concession to assure the reliability and quality of respondents, and the competence of an individual to detect signs was controlled for in the model. 
TABLE 1 Summary of best fitting models with $\Delta$ AIC $<4$, with Akaike Information Criterion (AIC), Akaike difference ( $\Delta$ AIC), Akaike weight, standard error in probability of occupancy $(\Psi)$ and standard error in probability of detection $(\mathrm{p})$.

\begin{tabular}{|c|c|c|c|c|c|}
\hline Model $^{\star}$ & AIC & $\Delta \mathrm{AIC}$ & Akaike weight (\%) & $\Psi \mathrm{SE}$ & $\mathrm{p}$ SE \\
\hline $\mathrm{p}(\mathrm{C}+\mathrm{YW}+\mathrm{G}+\mathrm{Y}) \Psi(\mathrm{V}+\mathrm{Ri}+\mathrm{Ro}+\mathrm{E}+\mathrm{G})$ & $1,349.16$ & 0.00 & 24 & 0.73 & 0.42 \\
\hline $\mathrm{p}(\mathrm{C}+\mathrm{YW}+\mathrm{G}+\mathrm{Y}) \Psi(\mathrm{V}+\mathrm{Ri}+\mathrm{Ro}+\mathrm{E}+\mathrm{S}+\mathrm{G})$ & $1,349.57$ & 0.41 & 20 & 0.7 & 0.4 \\
\hline $\mathrm{p}(\mathrm{C}+\mathrm{YW}+\mathrm{G}+\mathrm{Y}) \Psi(\mathrm{V}+\mathrm{Ri}+\mathrm{Ro}+\mathrm{E}+\mathrm{S})$ & $1,350.16$ & 1.00 & 15 & 0.29 & 0.35 \\
\hline $\mathrm{p}(\mathrm{C}+\mathrm{YW}+\mathrm{G}+\mathrm{Y}) \Psi(\mathrm{V}+\mathrm{Ri}+\mathrm{Ro}+\mathrm{E})$ & $1,350.24$ & 1.08 & 14 & 0.28 & 0.36 \\
\hline $\mathrm{p}(\mathrm{C}+\mathrm{YW}+\mathrm{G}+\mathrm{Y}) \Psi(\mathrm{V}+\mathrm{Ri}+\mathrm{Ro}+\mathrm{S})$ & $1,350.29$ & 1.14 & 14 & 0.3 & 0.35 \\
\hline $\mathrm{p}(\mathrm{C}+\mathrm{YW}+\mathrm{G}+\mathrm{Y}) \Psi(\mathrm{T}+\mathrm{V}+\mathrm{Ri}+\mathrm{Ro}+\mathrm{S})$ & $1,350.34$ & 1.19 & 13 & 0.3 & 0.35 \\
\hline
\end{tabular}

${ }^{*}$ p, probability of detection; C, nights camped; YW, years worked; G, forest management unit group; Y, year; $\Psi$, probability of occupancy; V, distance from village; $\mathrm{Ri}$, distance from river; Ro, distance from road; $\mathrm{E}$, elevation; $\mathrm{S}$, slope; $\mathrm{T}$, distance from town.

Therefore, we do not attribute spatio-temporal changes in detectability to spatial or temporal variations in the ability of respondents to detect elephants. It is likely that variation in the detectability of forest elephants is a valid proxy for variation in abundance, rather than variation in an ability to detect elephant signs. Site-level detectability, therefore, may be a signal of the relative abundance of elephants in occupied sites, suggesting that elephants are more abundant in the south-western and south-eastern forest management unit groups than elsewhere (Supplementary Fig. 1) but that abundance may be decreasing over time in the study area as a whole (Table 2, Fig. 2).

Detectability decreased by c. $30 \%$ between 2008 and 2013, which can be translated into a potential reduction in relative abundance of c. $40 \%$ (Fig. 2). Although the model shows no significant difference in occupancy related to the forest management unit groups, there is a significant difference in detectability between the groups. The confidence limits for occupancy were wide (Fig. 3), which is why the difference in occupancy is not significant. In contrast, the confidence limits for detectability were narrow for the central, southwestern and south-eastern forest management unit groups, and there is a significant difference in detectability between the forest management unit groups. However, the confidence limits for detectability in the northern forest management unit group are as wide as those for occupancy. This may be because of the low number of interviews at these sites, and therefore the interpretation of data from the northern forest management unit group should be treated with caution.

Administrative authorities and timber concession workers reported that elephants move around within the forest management units to distance themselves from villages (Buij et al., 2007; de Boer et al., 2013) and the noise of logging (also reported by Bowles et al., 1994; Richardson et al., 1995). However, it was reported that elephants did not move out of the forest management units because of their proximity to villages, and major roads that separate the units, particularly in the central and northern areas, where sites of high predicted occupancy are more isolated than in the more southerly regions (Fig. 1).

\section{Discussion}

Most of the detectability covariates relate to the ability of the respondent to notice and recall signs of forest elephants; however, the forest management unit group and year provide insights into abundance in occupied sites. The data show a decline in detectability because there was a decline in detections over the 6-year study period. All sites have a similar environment, activity level and level of visibility, and observer variables are controlled for in the model.

Respondent recall must be considered when gathering data covering a long period of time; however, with the survey design and cross-checking of responses, we do not believe recall to be a significant contributor to temporal changes in detectability. It is perhaps more sensible to conclude that the declining detectability over 6 years suggests a decline in abundance, which is supported by qualitative reports of a perceived decline in elephant abundance across the whole region, and reports of increased elephant poaching. Our estimates of occupancy and detectability from the null-model $(\Psi=0.76 \pm \mathrm{SE} 0.03, \mathrm{P}=0.59 \pm \mathrm{SE}$ o.o1; Supplementary Table 6) are comparable with those of Martinez Marti, (2011) in neighbouring Equatorial Guinea $(\Psi=0.44 \pm$ SE $0.03, \mathrm{P}=0.86 \pm$ SE 0.01$)$. The pattern of declining relative abundance is consistent with the findings of Maisels et al. (2013), and also with data from the CITES Monitoring the Illegal Killing of Elephants project, which show the estimated proportion of elephants killed illegally in Central Africa remained consistently above the sustainable level over the study period (CITES, 2015). The only sites with a likelihood of occupancy of $>0.6$ in the northern forest management unit group are adjacent to Mbam \& Djerem National Park (Fig. 1), suggesting that elephant populations living in Mbam \& Djerem may be using the north of the timber concession as a corridor for access to Deng Deng National Park (Supplementary Fig. 1). The same pattern of elevated likelihood of use in sites adjacent to Boumba Bek National Park is evident for the south-western group.

We have addressed a major knowledge gap concerning elephant distribution across a region of previously 
TABLE 2 Beta summary of best fitting model of occupancy and detectability of forest elephants Loxodonta cyclotis in timber production forests in eastern Cameroon (Fig. 1) p $(\mathrm{C}+\mathrm{YW}+\mathrm{G}+\mathrm{Y}) \Psi(\mathrm{V}+\mathrm{Ri}+\mathrm{Ro}+\mathrm{E}+\mathrm{G})$, with occupancy and detectability covariates.

\begin{tabular}{|c|c|c|c|c|}
\hline & Estimate & SE & $\mathrm{Z}$ & $\mathrm{P}(>|z|)$ \\
\hline \multicolumn{5}{|l|}{ Occupancy, $\Psi$} \\
\hline Intercept $(\mathrm{G}=$ Central $)$ & 2.47 & 0.65 & 3.82 & $<0.001$ \\
\hline Distance from village $(\mathrm{V})$ & 0.80 & 0.31 & 2.47 & 0.06 \\
\hline Distance from road (Ro) & 0.94 & 0.49 & 2.37 & 0.02 \\
\hline Distance from river $(\mathrm{Ri})$ & -0.48 & 0.22 & 2.30 & 0.03 \\
\hline Elevation (E) & -1.06 & 0.49 & 1.64 & 0.02 \\
\hline UFA group ( $\mathrm{G}$ contrast $\mathrm{SW}$ ) & 0.74 & 0.72 & 1.01 & 0.31 \\
\hline UFA group ( $\mathrm{G}$ contrast SE) & -1.4 & 1.05 & 1.26 & 0.17 \\
\hline UFA group (G contrast $\mathrm{N}$ ) & -3.75 & 2.16 & 1.91 & 0.07 \\
\hline \multicolumn{5}{|l|}{ Detectability, p } \\
\hline Intercept $(C=>8$ nights, $Y W=>10$ years, $G=$ Central, $Y=2008)$ & 0.98 & 0.36 & 2.70 & 0.006 \\
\hline Nights camped (C contrast $1-7)$ & -1.16 & 0.22 & 4.97 & $<0.001$ \\
\hline Years worked (YW contrast <10) & -0.09 & 0.16 & 0.60 & 0.54 \\
\hline Forest management unit group (G contrast SW) & 0.745 & 0.20 & 4.00 & 0.00 \\
\hline Forest management unit group (G contrast SE) & 2.34 & 0.18 & 12.73 & 0.00 \\
\hline Forest management group ( $\mathrm{G}$ contrast $\mathrm{N}$ ) & -0.84 & 1.63 & 1.20 & 0.61 \\
\hline Year (Y contrast 2009) & -0.77 & 0.41 & 1.93 & 0.06 \\
\hline Year (Y contrast 2010) & -0.86 & 0.38 & 2.37 & 0.02 \\
\hline Year (Y contrast 2011) & -1.02 & 0.36 & 2.86 & 0.01 \\
\hline Year (Y contrast 2012) & -1.28 & 0.35 & 3.73 & 0.00 \\
\hline Year (Y contrast 2013) & -1.07 & 0.36 & 3.06 & 0.003 \\
\hline
\end{tabular}

unsurveyed timber production forest, finding that forest elephant range extends further north and east of the 2012 known elephant range (Fig. 1), extending into areas deemed 'unlikely' by IUCN. Therefore, we recommend that the IUCN known elephant range be extended, and further surveys conducted in timber concessions in which elephants have been detected. In particular, sites adjacent to protected areas are potentially of high conservation value, and therefore it is important to work closely with timber concession companies to develop sustainable logging approaches and anti-poaching activities to help protect forest elephants.

High levels of occupancy throughout the south-eastern and south-western forest management unit groups, and a high likelihood of occupancy in sites adjacent to National Parks (as also suggested by Lamb et al., 2005) in the north, support the suggestion that well-managed timber concessions can provide refuge to forest elephants in an otherwise insecure landscape (Weinbaum et al., 2007; Clark et al., 2009; Kolowski, 2010; Stokes et al., 2010). However, the emphasis on 'well-managed' means that additional support should be provided to concessions with a high likelihood of occupancy, to improve their sustainability practices and ensure that they can continue to operate in a manner that minimizes the impact on remaining elephant populations.

Despite the high levels of occupancy in some sites, the detectability (and therefore relative abundance) is low in comparison to that observed elsewhere (Martinez Marti, 2011) possibly indicating relatively low abundance in occupied sites, and further highlighting the importance of conservation action in these sites. For example, our findings suggest that it would be useful to carry out a more detailed survey in key concession units around protected areas in the north, which appear to be acting as de facto corridors. Such surveys could inform actions to develop more formal corridors to ensure the sustainability of these populations, which currently appear to be isolated and potentially unviable in the longer term.

The informal interviews and open-ended questions highlighted some key issues, in particular the high financial value of ivory, the lack of comparable alternative livelihoods in the face of increasing international demand, the lack of law enforcement, and high levels of corruption (Supplementary Material 2).

Sampling in this rapid assessment was limited to sites in which timber concession workers had been prospecting or exploiting, and consequently the sites mostly changed each year, as each site represented an area of annual exploitation, and the impacts of exploitation could not be explored, as variation in exploitation category (pre/during/post exploitation) was not available. Applying this approach in situations in which respondents' spatial frames of reference are more spatially stable would be desirable to support multi-season occupancy modelling (Royle \& Kéry, 2007), potentially facilitating a more sophisticated analysis of the dynamics of occupancy over time.

Occupancy estimates are generally in line with the observed detection histories and with perceived abundance. 

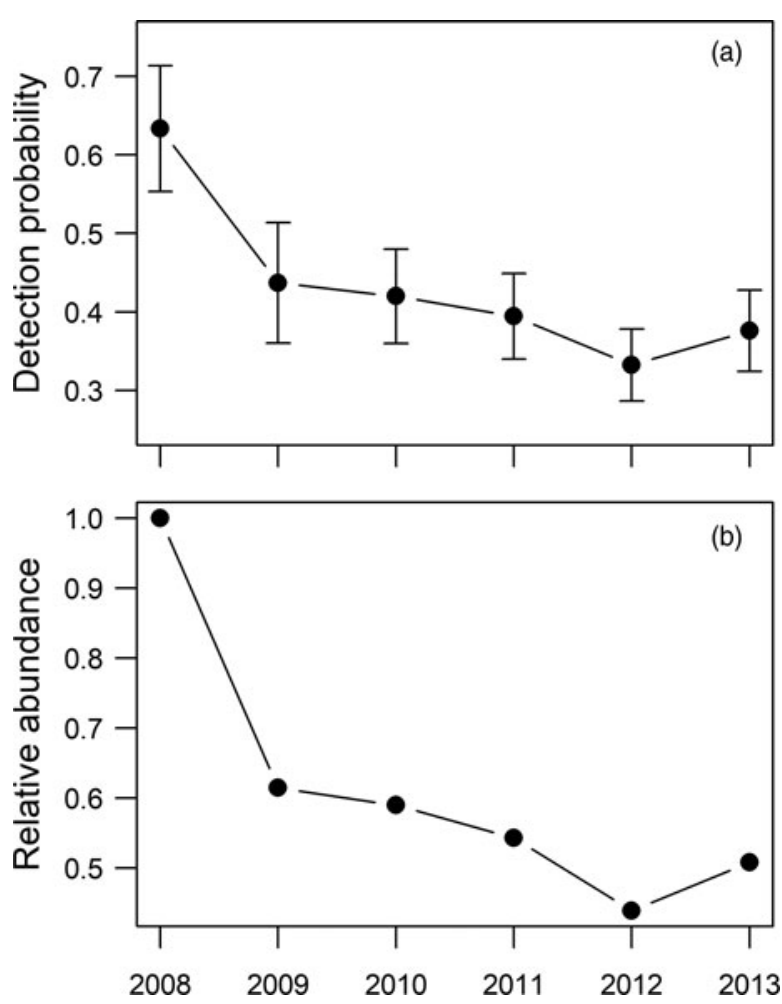

FIG. 2 (a) Detection probability and (b) relative abundance of forest elephants Loxodonta cyclotis in the study area in eastern Cameroon during 2008-2013.

However, there are areas where the occupancy predictions do not match actual observations. Areas of underrepresentation within the detection/non-detection data may be an influencing factor. Alternatively, heterogeneity caused by incomplete overlap between home range and site may influence the probability of detecting an individual, as does the number of elephants within each plot. As a result, the relationship between the distribution of sampling effort and elephant home ranges may account for some variation between the naïve pattern and the predicted occupancy (Efford \& Dawson, 2012).

Despite these potential sources of uncertainty, our findings suggest that interview-based occupancy analysis is a reliable method for the rapid assessment of forest elephant occupancy at large spatio-temporal scales and in challenging forest habitat, as a complement to, or first stage in, a monitoring process (Meijaard et al., 2011). Using this method we were able to gain new insights into the distribution and trends in forest elephant populations at a large scale, effectively surveying c. $30,000 \mathrm{~km}^{2}$ in 10 weeks on a budget of GBP 2,00o. We also produced contextual qualitative insight data, providing a socio-demographic context that can inform subsequent conservation planning.

This approach is best suited to surveying large, remote areas that potential informants visit on a regular basis, for poorly known but easily recognizable species (Meijaard et al., 2011). Several authors (e.g. Pan et al., 2015; Nash

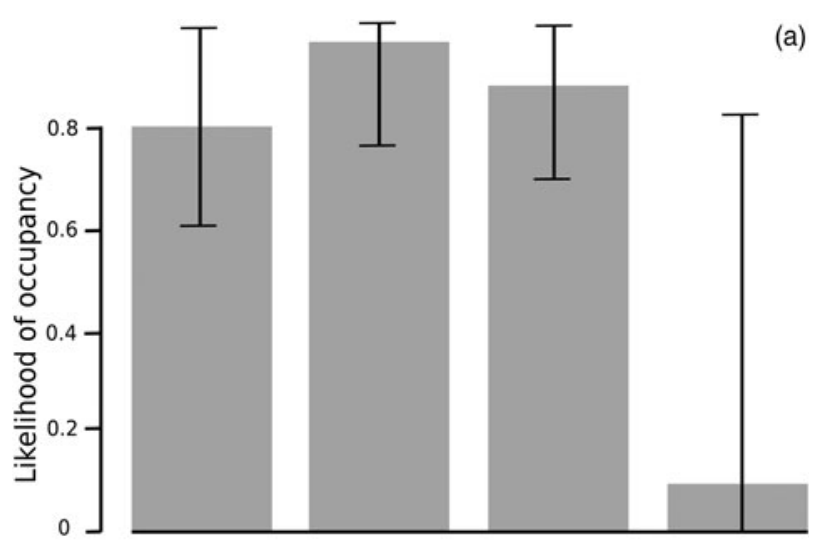

(b)

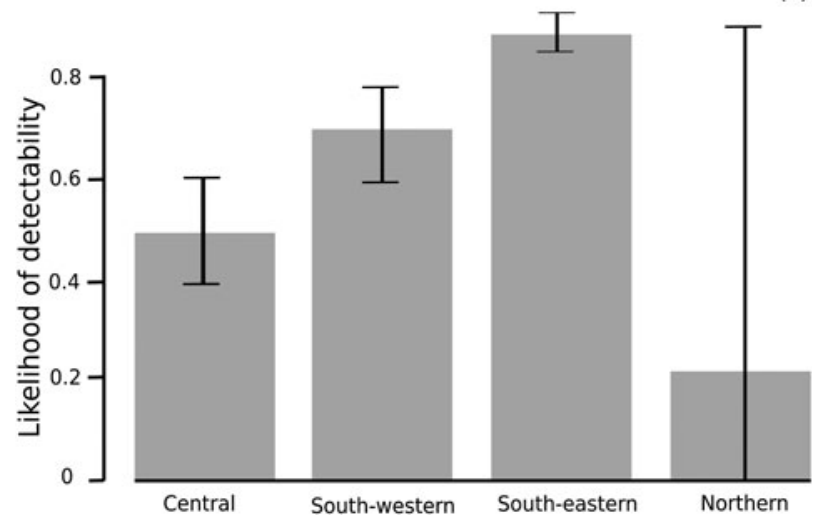

FIG. 3 Likelihood of (a) occupancy and (b) detectability ( \pm SE) of forest elephants across the study area in eastern Cameroon during 2008-2013.

et al., 2016) have used sightings by local people to infer changes in presence or abundance of species with these characteristics. However, with the addition of an occupancy modelling framework to structure and analyse observational datasets, more robust inferences may be drawn, specifically about detection-corrected occupancy, its covariates (such as geographical factors) and, through spatio-temporal changes in detectability, trends in relative abundance. The additional requirements for using an occupancy approach are not onerous: they include collecting information about potential observer effects (such as time spent in the forest), and biophysical variables, ensuring at least four repeat observations per sampling unit, and choosing sample units that are familiar to the respondents, to collect spatially accurate data.

\section{Acknowledgements}

We thank ZSL Cameroon for their assistance during data collection, and Imperial College London for financial support. The work was supported by a NERC-CASE studentship to SB. Datasets are available on request from the corresponding author. 


\section{Author contributions}

SB and MNB collected the data. SB designed the study and conducted analysis, with guidance from MR and PDO. SB led the publication of the article, with support and editing from EJMG and MR and input from the whole team.

\section{References}

Abram, N.K., Meijaard, E., Wells, J.A., Ancrenaz, M., Pellier., A-S., Runting, R.K. et al. (2015) Mapping perceptions of species' threats and population trends to inform conservation efforts: The Bornean orangutan case study. Diversity and Distributions, 21, 487499.

Bailey, L.L., Simons, T.R. \& Pollock, K.H. (2004) Estimating site occupancy and species detection probability parameters for terrestrial salamanders. Ecological Applications, 14, 692-702.

BARNES, R.F.W. (2001). How reliable are dung counts for estimating elephant numbers? African Journal of Ecology, 38, 1-9.

Belant, J.L., Hofer, H. \& Wilting, A. (2013) Comparison of methods for detecting and surveying tropical carnivores. The Raffles Bulletin of Zoology, Supplement No. 28, 109-113.

Bikié, H., Collomb, J.G., Djomo, L., Minnemeyer, S., Ngoufo, R. \& Nguiffo, S. (2000) An Overview of Logging in Cameroon: A Global Forest Watch Cameroon Report. World Resources Institute, Washington, DC, USA.

B LAKe, S. (2005) Central African Forests: Final Report on Population Surveys (2003-2004). CITES Secretariat, Geneva, Switzerland.

Blake, S., Deem, S.L., Strindberg, S., Maisels, F., Momont, L., IsiA, I.B. et al. (2008) Roadless wilderness area determines forest elephant movements in the Congo Basin. PLoS ONE, 3(10), e3546.

Blake, S. \& Hedges, S. (2004) Sinking the flagship: the case of forest elephants in Asia and Africa. Conservation Biology, 18, 1191-1202.

Blake, S., Strindberg, S., Boudjan, P., Makombo, C., Bila-Isia, I., Ilambu, O. et al. (2007) Forest elephant crisis in the Congo Basin. PLoS Biology, 5(4), e111.

BLANC, J. (2008) Loxodonta africana. In The IUCN Red List of Threatened Species 2008: e.T12392A3339343. Http://dx.doi.org/10. 2305/IUCN.UK.2008.RLTS.T12392A3339343.en [accessed 13 October 2017].

Blanc, J.J., Barnes, R.F.W., Craig, G.C., Dublin, H.T., Thouless, C.R., Douglas-Hamilton, I. \& Hart, J.A. (2007) African Elephant Status Report: An Update from the African Elephant Database. Occasional Paper Series of the IUCN Species Survival Commission. Report number 33. IUCN, Gland, Switzerland.

Boafo, Y., Manford, M., B ARnes, R.F.W., Herma, E.M., Danquah, E., Awo, N \& Dubiure, U.F (2009) Comparison of two dung count methods for estimating elephant numbers at Kakum Conservation Area in southern Ghana. Pachyderm, 45 July 2008-June 2009, 34-40.

Bowles, A.E., Smultea, M., Wursig, B., Demaster, D.P. \& Palka, D. (1994). Relative abundance and behavior of marine mammals exposed to transmissions from the Heard Island Feasibility Test. Journal of the Acoustic Society of America, 96, 2469-2484.

Buckland, S.T., Anderson, D.R., Burnham, K.P., Laake, J.L., Thomas, L. \& Borchers, D. (2001) Introduction to Distance Sampling: Estimating Abundance of Biological Populations. Oxford University Press, Oxford, UK.

Buij, R., McShea, W.J., Campbell, P., Lee, M.E., Dallmeier, F., Guimondou, S. et al. (2007) Patch-occupancy models indicate human activity as major determinant of forest elephant Loxodonta cyclotis seasonal distribution in an industrial corridor in Gabon. Biological Conservation, 135, 189-201.

Burnham, K.P. \& Anderson, D.R. (2002) Model Selection and Multimodel Inference: A Practical Information-theoretic Approach. and edition. Springer-Verlag, New York, USA.

Cerqueira, M.C., Cohn-Haft, M., Vargas, C.F., Nader, C.E., Andretti, C.B., Costa, T.V.V. et al. (2013). Rare or elusive? A test of expert knowledge about rarity of Amazon forest birds. Diversity and Distributions, 19, 710-721.

Cerutti, P.O., Mbongo, M. \& Vandenhaute, M. (2016) State of the Timber Sector in Cameroon (2015). FAO/CIFOR. Http://www.fao. org/fileadmin/user_upload/FLEGT/docs/State_timber_sector_ 2015_CIFOR_MINFOF_FAOFLEGT.pdf [accessed 8 December 2017].

CITES (2015) Monitoring the Illegal Killing of Elephants: An Update on Elephant Poaching Trends in Africa to 31 December 2015. CITES Secretariat, Geneva, Switzerland.

Clark, C.J., Poulsen, J.R., Malonga, R. \& Elkan JR, P.W. (2009) Logging concessions can extend the conservation estate for Central African tropical forests. Conservation Biology, 23, 1281-1293.

Danielsen, F., Balete, D.S., Poulsen, M.K., Enghoff, M., Nozawa, C.M. \& Jensen, A.E. (2000) A simple system for monitoring biodiversity in protected areas of a developing country. Biodiversity and Conservation, 9, 1671-1705.

Danielsen, F., Burgess, N.D. \& Balmford, A. (2005) Monitoring matters: examining the potential of locally-based approaches. Biodiversity and Conservation, 14, 2507-2542.

Danielsen, F., Burgess, N.D., Jensen, P.M. \& Pirhofer-Walzl, K. (2010) Environmental monitoring: the scale and speed of implementation varies according to the degree of peoples' involvement. Journal of Applied Ecology, 47, 1166-1168.

De Boer, W.F., Langevelde, F.V., Prins, H.H.T., De Ruiter, P.C., BLANC, J., VIs, M.J.P. et al. (2013) Understanding spatial differences in African elephant densities and occurrence, a continent-wide analysis. Biological Conservation, 159, 468-476.

Douglas-Hamilton, I., Krink, T. \& Vollrath, F. (2005) Movements and corridors of African elephants in relation to protected areas. Die Naturwissenschaften, 92, 158-163.

D’Souza, E., Patankar, V., Arthur, R., Alcoverro, T. \& Kelkar, N. (2013) Long-term occupancy trends in a data-poor dugong population in the Andaman and Nicobar archipelago. PLoS ONE, 8 (10), e76181.

EFFord, M. \& Dawson, D.K. (2012) Occupancy in continuous habitat, Ecosphere, 3(4): 32 .

Fiske, I. \& Chandler, R. (2011) unmarked: An R package for fitting hierarchical models of wildlife occurrence and abundance. Journal of Statistical Software, 43(10), 1-23.

Hedges, S. (ed.) (2012) Monitoring Elephant Populations and Assessing Threats. A Manual for Researchers, Managers and Conservationists. Universities Press, Hyderabad, India.

IUCN/SSC (2013) African Elephant Specialist Group Database. Http://www.elephantdatabase.org/ [accessed 16 March 2015].

Jones, J.P.G., Andriamarovololona, M.M., Hockley, N., Gibbons, J.M. \& Milner-Gulland, E.J. (2008) Testing the use of interviews as a tool for monitoring trends in the harvesting of wild species. Journal of Applied Ecology, 45, 1205-1212.

Joseph, L.N., Field, S.A., Wilcox, C. \& Possingham, H.P. (2006) Presence-absence versus abundance data for monitoring threatened species. Conservation Biology, 20, 1679-1687.

Kolowski, J.M., Blake, S., Kock, M.D., Lee, M.E., Henderson, A., Honorez, A. \& Alonso, A. (2010) Movements of four forest elephants in an oil concession in Gabon, Central Africa. African Journal of Ecology, 1, 1134-1138 
Lamb, D., Erskine, P. D. \& Parrotta, J. (2005) Restoration of degraded tropical forest landscapes. Science. 310, 1628-32.

Lunn, K. \& Dearden, P. (2006) Monitoring small-scale marine fisheries: an example from Thailand's Ko Chang archipelago. Fisheries Research, 77, 60-71.

Karanth, K.U., Nichols, J.D., Seidensticker, J., Dinerstein, E., Smith, J.L.D., McDougal, C. et al. (2003) Science deficiency in conservation practice: the monitoring of tiger populations in India. Animal Conservation, 6, 141-146.

MacKenZie, D.I. (2006) Modelling the probability of resource use: the effect of, and dealing with, detecting a species imperfectly. The Journal of Wildlife Management, 70, 367-374.

MacKenzie, D.I. \& Bailey, L.L. (2004) Assessing the fit of site-occupancy models. Journal of Agricultural, Biological, and Environmental Statistics, 9, 300-318.

MacKenzie, D.I., Nichols, J.D., Hines, J.E., Knutson, M.G. \& FrankLIN, A.B. (2003) Estimating site occupancy, colonization and local extinction when a species is detected imperfectly. Ecology, 84 2200-2207.

MacKenzie, D.I., Nichols, J.D., Lachman, G.B., Droege, S., Royle, J.A. \& Langtimm, C.A. (2002) Estimating site occupancy rates when detection probabilities are less than one. Ecology, 83, 2248-2255.

MacKenzie, D.I., Nichols, J.D., Royle, J.A., Pollock, K.H., Bailey, L.L. \& Hines, J.E. (2006) Occupancy Estimation and Modeling: Inferring Patterns and Dynamics of Species Occurrence. Academic Press, Burlington, USA.

MacKenzie, D.I., Nichols, J.D., Seamans, M.E. \& Gutiérrez, R.J. (2009) Modelling species occurrence dynamics with multiple states and imperfect detection. Ecology, 90, 823-835.

MacKenzie, D.I. \& Royle, J.A. (2005) Designing occupancy studies: general advice and allocating survey effort. Journal of Applied Ecology, 42, 1105-1114.

Maisels, F., Strindberg, S., Blake, S., Wittemyer, G., Hart, J., Williamson, E.A. et al. (2013) Devastating decline of forest elephants in Central Africa. PLoS ONE, 8(3), e59469.

Martinez Marti, C. (2011) The Leopard (Panthera pardus) and the Golden Cat (Caracal aurata) in Equatorial Guinea: A National Assessment of Status, Distribution and Threat. Annual Report April 2010 to March 2011. Conservation International, Arlington, USA.

Meijaard, E., Mengersen, K., Buchori, D., Nurcahyo, A., Ancrenaz, M., Wich, S. et al. (2011) Why don't we ask? A complementary method for assessing the status of great apes. PLoS ONE, 6(3), e180o8.

Milliken, T., Burn, R.W. \& SAngalakula, L. (2009) The Elephant Trade Information System (ETIS) and the illicit trade in ivory (CoP15 Doc. 44.1 Annex). Http://www.cites.org/sites/default/files/common/ cop/15/doc/E15-44-01A.pdf [accessed 1o March 2013].

Mohd-Azlan, J., Belant, J. L. \& Meijaard, E. (2013) Can secondary information inform about population trends of carnivores in Borneo? The Raffles Bulletin of Zoology, Supplement no. 28, 1-8.

Moller, H., Berkes, F., O’Brian Lyver, P. \& Kislalioglu, M. (2004) Combining science and traditional ecological knowledge: monitoring populations for co-management. Ecology and Society, 9 (3), 2.

Nash, H.C., Wong, M.H.G. \& Turvey, S.T. (2016). Using local ecological knowledge to determine status and threats of the Critically Endangered Chinese pangolin (Manis pentadactyla) in Hainan, China. Biological Conservation 196, 189-195.

Newing, H., Eagle, C.M., Puri, R.K. \& Watson, C.W. (2011) Constructing Research in Conservation: A Social Science Perspective. Routledge, Abingdon, UK.

Ngene, S.M., Skidmore, A.K., Van Gils, H., Douglas-Hamilton, I. \& OMONDI, P. (2009) Elephant distribution around a volcanic shield dominated by a mosaic of forest and savanna (Marsabit, Kenya). African Journal of Ecology, 47, 234-245.

Nuno, A., Bunnefeld, N. \& Milner-Gulland, E. J. (2013) Matching observations and reality: using simulation models to improve monitoring under uncertainty in the Serengeti. Journal of Applied Ecology, 50, 488-498.

Pan, Y., Cunningham, A.A. \& Milner-Gulland, E.J. (2015) Using local ecological knowledge to assess the status of the Critically Endangered Chinese giant salamander Andrias davidianus in Guizhou Province, China. Oryx, 50, 257-264.

Parry, L \& Peres, C. A. (2015) Evaluating the use of local ecological knowledge to monitor hunted tropical-forest wildlife over large spatial scales. Ecology and Society, 20(3), 15.

Pillay, R., Johnsingh, A.J.T., Raghunath, R. \& Madhusudan, M.D. (2011) Patterns of spatiotemporal change in large mammal distribution and abundance in the southern Western Ghats, India. Biological Conservation, 144, 1567-1576.

Puri, M., Srivathsa, A., Karanth, K.K., Kumar, N.S. \& Karanth, K.U. (2015) Multiscale distribution models for conserving widespread species: the case of sloth bear Melursus ursinus in India. Diversity and Distributions, 21, 1087-1100.

R Development Core Team (2017) R: A Language and Environment for Statistical Computing. R Foundation for Statistical Computing, Vienna, Austria.

Richardson, W.J., Greene Jr, C.R., Malme, C.I. \& Thomson, D.H. (1995) Marine Mammals and Noise. Academic Press, San Diego, USA.

Royle, J.A. \& Kéry, M. (2007) A Bayesian state-space formulation of dynamic occupancy models. Ecology, 88, 1813-1823.

Royle, J.A. \& Nichols, J.D. (2003) Estimating abundance from repeated presence-absence data or point counts. Ecology, 84, 777790.

SAPSFORD, R. \& Jupp, V. (eds) (1996) Data Collection and Analysis. Sage, London, UK.

Schuttler, S.G., Blake, S. \& Eggert, L.S. (2012) Movement patterns and spatial relationships among African forest elephants. Biotropica, $44,445-448$.

Service, C.N., Adams, M.S., Artelle, K.A., Paquet, P., Grant, L. V. \& Darimont, C.T. (2014) Indigenous knowledge and science unite to reveal spatial and temporal dimensions of distributional shift in wildlife of conservation concern. PLoS ONE, 9(7), e101595.

Sethi, G., Costello, C., Fisher, A., Hanemann, M. \& Karp, L. (2005) Fishery management under multiple uncertainty. Journal of Environmental Economics and Management, 50, 300-318.

Social Research Association (2003) Ethical Guidelines, 2003. Http://www.the-sra.org.uk [accessed 4 March 2013].

Stokes, E.J., StrindberG, S., Bakabana, P.C., Elkan, P.W., Iyenguet, F.C., Madzoké, B. et al. (2010) Monitoring great ape and elephant abundance at large spatial scales: measuring effectiveness of a conservation landscape. PLoS ONE, 5(4), e10294.

Sutherland, W.J. (2006) Ecological Census Techniques: A Handbook. 2nd edition. Cambridge University Press, Cambridge, UK.

Sutherland, W.J., Pullin, A.S., Dolman, P.M. \& Knight, T.M. (2004) The need for evidence-based conversation. Trends in Ecology and Evolution, 19, 305-308.

Tracey, J.P., Fleming, P.J., \& Melville, G.J. (2005) Does variable probability of detection compromise the use of indices in aerial surveys of medium-sized mammals? Wildlife Research, 32, 245-252.

Turvey, S.T., Barrett, L.A., Yujiang, H., Lei, Z., Xinqiao, Z., XIAnyan, W. et al. (2010) Rapidly shifting baselines in Yangtze fishing communities and local memory of extinct species. Conservation Biology, 24, 778-787.

Turvey, S.T., Fernandez-Secades, C., Nunez-Mino, J.M., Martinez, P., Brocca, J.L \& Young, R.P. (2014). Is local 
ecological knowledge a useful conservation tool for small mammals in a Caribbean multicultural landscape? Biological Conservation, $169,189-197$.

Turvey, S.T., Risley, C.L., Moore, J.E., Barrett, L.A., Yujiang, H., XIUjIANG, Z. et al. (2013) Can local ecological knowledge be used to assess status and extinction drivers in a threatened freshwater cetacean? Biological Conservation, 157, 352-360.

Turvey, S.T., Trung, C.T., Quyet, V.D., Nhu, H.V., Thoai, D.V., TuAN, V.C.A. et al. (2015) Interview-based sighting histories can inform regional conservation prioritization for highly threatened cryptic species. Journal of Applied Ecology, 52, 422-433.

Vira, V., Ewing, T. \& Miller, J. (2014) Out of Africa: Mapping the Global Trade in Illicit Ivory. Born Free Foundation. Http://www. bornfree.org.uk/fileadmin/user_upload/files/reports/elephants/ Out-of-Africa-2014.pdf [accessed 16 March 2015].

Walsh, P.D., Thibault, M., Minindou, Y., Idiata, D., Mbina, C. \& White, L.J.T. (200o) A statistical framework for monitoring forest elephants. Natural Resource Modeling, 13, 89-134.

Weinbaum, K., Nzooh Dongmo, Z L., Usongo, L. \& Laituri, M. (2007) Preliminary survey of forest elephant crossings in Sangha Trinational Park, central Africa. Pachyderm, 43, 52-62
Wintle, B.A., Walshe, T.V., Parris, K.M. \& McCarthy, M.A. (2012) Designing occupancy surveys and interpreting non-detection when observations are imperfect. Diversity and Distributions, 18, 417-424.

Yackulic, C.B., Strindberg, S., Maisels, F. \& Blake, S. (2011) The spatial structure of hunter access determines the local abundance of forest elephants (Loxodonta africana cyclotis). Ecological Applications, 21, 1296-1307.

\section{Biographical sketches}

STEPHANIE BRItTAIN's research interests lie in the use of local knowledge for wildlife population monitoring. Madeleine NGO Bata monitors threatened species in timber forest concessions in Cameroon. PaUl De ORnellas focuses on the illegal wildlife trade, and improvement of monitoring within reserves across Africa. E.J. MilneR-Gulland has a broad range of interests in interdisciplinary conservation science (her research group page is at http://www.iccs.org. uk). MARCUS ROWCLIFFE is a conservation scientist interested in improving methods for the monitoring of elusive and threatened species. 